\title{
Electrical, Thermal and Mechanical Properties of Epoxy/CNT/Calcium Carbonate Nanocomposites
}

\author{
Eduardo Henrique Backes ${ }^{*}$, Tarcísio Sanson Sene ${ }^{a}$, Fabio Roberto Passador $^{b}$, Luiz Antonio Pessan $^{a}$ \\ ${ }^{a}$ Departamento de Engenharia de Materiais, Universidade Federal de São Carlos, via Washington Luiz, \\ Km 235, 13565-905, São Carlos, SP, Brasil.

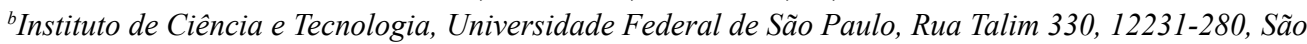 \\ José dos Campos, SP, Brasil.
}

Received: September 05, 2017; Revised: October 09, 2017; Accepted: October 18, 2017

Epoxy/CNT and epoxy/CNT/calcium carbonate nanocomposites were produced via in situ polymerization assisted by ultrasonication without solvent and electrical, mechanical, thermal and thermomechanical properties of nanocomposites were evaluated. Epoxy/CNT presented very low percolation threshold, near $0.05 \mathrm{wt} \%$ and nanocomposites with higher contents of CNT presented further increase in electrical conductivity. The addition of calcium carbonate in epoxy/CNT nanocomposites increased the electrical conductivity, due to volume exclusion phenomena. Regarding thermal properties, due to the low content of the CNT and calcium carbonate no changes in glass transition ( $\mathrm{Tg}$ ) were observed. DMA results showed no significant changes in thermomechanical properties, once the contents of CNT and calcium carbonate are below stiffness threshold, however an increase of flexural modulus by adding CNT and calcium carbonate was observed.

Keywords: Epoxy nanocomposites, MWCNT, dielectrical properties.

\section{Introduction}

Carbon nanotubes (CNT) are a very promising material due to its outstanding mechanical, thermal and electrical properties $^{1,2}$. Since their discovery by Ijima, several studies dispersing carbon nanotubes in polymer matrix have been conducted aiming to explore the entire potential of the carbon nanotubes ${ }^{3-6}$. However, to reach this goal it is necessary to enhance carbon nanotubes dispersion and reduce the CNT breaking during processing ${ }^{7,8}$. A high shear stress process is required to disperse and disentangle carbon nanotubes into polymer matrix; however, the shear stress applied should be between the linkage energy of carbon nanotubes bundles and the fracture energy of individual carbon nanotubes ${ }^{9,10}$.

Epoxy matrix was one of the first matrix reinforced with carbon nanotubes and ever since several studies using different dispersion techniques, carbon nanotubes treatments and hybrid reinforcements have been investigated ${ }^{11-14}$. Ultrasonication is one of the most used processing method for dispersing carbon nanotubes in epoxy, however it is only effective in low viscosity matrix, e.g., matrix for in situ polymerization or diluted with solvent $t^{1,7,10,15}$. Low viscosity matrix aids CNT dispersion during ultrasonication, hence is possible to accomplish low electrical percolation threshold without the use of solvent. During ultrasonication shear strain rates can reach up to $10^{-9} / \mathrm{s}^{10,16,17}$.

The electrical percolation threshold obtained in epoxy/ CNT nanocomposites is one of lowest among the conductive nanocomposites, and can be described using a simple power law equation ${ }^{18}$. The Equation 1 is a power law equation which describes the relation between the electrical conductivity of the nanocomposites and CNT concentration, where $\sigma_{\mathrm{m}}$ is the nanocomposite electrical conductivity, $\sigma_{\mathrm{h}}$ is the carbon nanotubes electrical conductivity $\left(10^{4} \mathrm{~S} / \mathrm{m}\right), \theta$ is volume fraction of the carbon nanotubes in the nanocomposite, $\theta_{c}$ is the percolation threshold and $t$ is the critical exponent, which can be related to dispersion of $\mathrm{CNT}^{19-21}$.

$$
\mathbf{B}=\mathbf{a},\left(\mathbf{B}-\mathbf{\theta}_{\mathbf{a}}\right)
$$

The electrical conductivity of the nanocomposites is dependent of the carbon nanotubes electrical conductivity, the content of the carbon nanotubes, aspect ratio and its percolation threshold at host matrix. According to Russ et al. when carbon nanotubes are well dispersed in the polymeric matrix, the carbon nanotubes with high aspect ratio tend to lower percolation threshold due to a lower number of contacts needed to reach percolation when compared to shorter carbon nanotubes ${ }^{19}$. Ayatollahi et al. investigated the effect of carbon nanotubes aspect ratio on electrical conductivity of several epoxy/CNT nanocomposites and concluded that nanocomposites containing high aspect ratio carbon nanotubes presented higher electrical conductivity ${ }^{22}$.

Liu and Grunlan also investigated the addition of montmorillonite (MMT) in epoxy/CNT nanocomposites as an alternative to reduced carbon nanotubes electrical percolation threshold and increase electrical conductivity ${ }^{23}$. According the authors, the addition of montmorillonite in epoxy/CNT 
nanocomposites can affect CNT dispersion and under 2 different mechanisms reduces the electrical percolation threshold. First, the addition of montmorillonite reduces the free volume available for CNT in the matrix, creating carbon nanotubes pathways that are segregated ${ }^{23}$. The second argument is that after the ultrasonication of the epoxy/CNT/MMT mixture, the presence of montmorillonite increases the viscosity of the nanocomposite before curing, and during the cooling, the montmorillonite prevents migration and reaglomeration of carbon nanotubes. Finally, micrographs showed that the carbon nanotubes might interact with montmorillonite, once carbon nanotubes surround the montmorillonite aggregates.

Bao et al. obtained similar results as Liu and Grunlan; however, they analyzed the addition of calcium carbonate in Polypropylene/CNT nanocomposites ${ }^{24}$. According to the authors, the addition of calcium carbonate reduced the electrical percolation threshold in PP/CNT nanocomposites, once the calcium carbonate reduced the free volume available for the CNT.

Concerning the mechanical and thermal properties of epoxy/CNT nanocomposites, Montazeri and Chitsazzadeh observed variation in Young Modulus from -14.6\% to 46.5 $\%$ with the addition of CNT when compared to neat epoxy ${ }^{25}$. It was also observed an increase in $\mathrm{T}_{\mathrm{g}}$ up to $6.6^{\circ} \mathrm{C}$ by $\mathrm{CNT}$ addition when compared to neat epoxy.

Vahedi et al. studied mechanical and electrical properties of epoxy/CNT nanocomposites produced via ultrasonication ${ }^{26}$. In the nanocomposites with $0.1 \mathrm{wt} \%$ of CNT, it was observed an increase of $18.8 \%$ in flexural strength, reaching the maximum flexural strength with $0.25 \mathrm{wt} \%$ of CNT. Despite the improvement in mechanical properties, the nanocomposites only revealed improvements in electrical properties for CNT loadings higher than $0.5 \mathrm{wt} \%$.

In this work, epoxy/CNT/ calcium carbonate with different contents of CNT and calcium carbonate were produced using ultrasonication. The electrical percolation threshold of epoxy/CNT nanocomposites was determined and the influence of the addition of calcium carbonate in the electrical, mechanical and thermal properties of epoxy/ CNT nanocomposites was analyzed.

\section{Experimental}

\subsection{Materials}

Diglycidyl ether of bisphenol-A (DGEBA), a typical commercial epoxy resin (trade name: Araldite LY 1316) and amine hardener (trade name: Aradur HY 1208) were supplied by Hunstman. It was used $13 \mathrm{phr}$ (parts per hundred resin) of hardener, according to the supplier recommendation. In order to avoid bubbles formation, two silicone-free anti foaming agents, A 560 and A 500, were used. BYK chemicals donated both anti foaming agents.
Superfine calcium carbonate (trade name: XM 303) was supplied by YHnano and it is a white powder with particle size in the order of 70-90 nm and density of 2.65-2.7 $\mathrm{g} \mathrm{cm}^{-3}$.

The multi-walled carbon nanotubes (CNT) designed as NC7000 were supplied by Nanocyl S.A. This CNT has purity above $90 \%$, average outer diameter of $9.5 \mathrm{~nm}$ and length of $1.5 \mu \mathrm{m}$.

\subsection{Preparation of Epoxy/CNT nanocomposites}

The processing technique used for dispersion of both CNT and calcium carbonate into epoxy was ultrasonication. First, epoxy, CNT and calcium carbonate were manually mixed together and ultrasonicated using a sonicator Sonics Vibra-Cell model VC 505 (solid probe) in a $150 \mathrm{ml}$ vessel for $30 \mathrm{~min}$ at $200 \mathrm{~W}$. For each composition, the proportion of epoxy was $100 \mathrm{~g}$. After the sonication, the mixture was cooled and transferred to a buchner flask. In this flask, 0.5 wt $\%$ of each degassing agent was added while the mixture was kept under magnetic stirring. At the end, hardener was added and after 30 min of mixing and degassing, the mixture was poured in silicone molds. The samples were cured for 7 days at $25^{\circ} \mathrm{C}$ and a post-cured for $4 \mathrm{~h}$ at 80 ${ }^{\circ} \mathrm{C}$. The samples dimensions were 127 (L) x 12.6 (W) $\mathrm{x}$ $3.2(\mathrm{~T}) \mathrm{mm}^{3}$.

\subsection{Nanocomposites Formulation}

In this work, 3 different types of formulations were studied: neat epoxy, epoxy/CNT and epoxy/CNT/calcium carbonate. Epoxy/CNT nanocomposites were produced using $0.05,0.1,0.2$ and $0.3 \mathrm{wt} \%$ of $\mathrm{CNT}$, respectively $\mathrm{C} 1$, $\mathrm{C} 2, \mathrm{C} 3$ and $\mathrm{C} 4$. For the preparation of epoxy/CNT/calcium carbonate nanocomposites, it were used CNT contents of 0.05 and $0.1 \mathrm{wt} \%$ (covering the electrical percolation threshold) and a constant calcium carbonate content of 1 wt $\%$, respectively these nanocomposites are $\mathrm{C} 1 \mathrm{C}$ and $\mathrm{C} 2 \mathrm{C}$. The content of calcium carbonate was set following the proportions between $\mathrm{CNT}$ and calcium carbonate in the nanocomposites produced by Bao et al. ${ }^{24}$

\subsection{Nanocomposites Characterization}

Transmission Electron Microscopy (TEM): Morphological characterization of the nanocomposites was performed using TEM. The samples were cryogenic cut using an ultramicrotome (Riechert-Jung model Ultracut E) and a diamond knife. The thickness was set $50 \mathrm{~nm}$ and the images were obtained using a transmission electron microscope Philips, model CM120 and acceleration voltage of $120 \mathrm{kV}$.

AC Impedance spectroscopy: The electrical properties of the nanocomposites were measured by the two-point method using an AC impedance analyzer Solartron, model 1260A, linked to a dielectric interface system, model 1296. The tests were performed from $1 \mathrm{~Hz}$ to $1 \mathrm{GHz}$, using voltage amplitude of $1 \mathrm{~V}$. The samples were polished and the final thickness was between $1.8-2.0 \mathrm{~mm}$. Silver paint was 
applied in both sides of the samples and the area covered was kept constant at $78 \mathrm{~mm}^{2}$. Three samples were tested for each composition and the electrical conductivity $(\sigma)$ of the samples was determined using Equation 2, where $\mathrm{S}$ is the thickness of the sample, A is the area covered with silver paint and $\mathrm{R}$ is the real impedance.

$$
\sigma=\frac{S}{\left(R^{* A}\right)}
$$

Differential Scanning Calorimetry (DSC): The DSC was performed using an equipment from TA Instruments, model QS100. The samples were heated from $30{ }^{\circ} \mathrm{C}$ to 200 ${ }^{\circ} \mathrm{C}$ using a heating rate of $10^{\circ} \mathrm{C} / \mathrm{min}$. The atmosphere was kept inert (nitrogen flow of $50 \mathrm{~mL} / \mathrm{min}$ ), the weight of the samples ranged between 5-10 $\mathrm{mg}$ and three specimens were tested for each composition.

Dynamic Mechanical Analysis (DMA): The dynamic mechanical properties were evaluated using an equipment from TA instruments, model Q800. The tests were performed using three point bending mode ( $8 \mathrm{lb}$.in) and the following conditions: oscillation frequency of $1 \mathrm{~Hz}$, heating rate of $3{ }^{\circ} \mathrm{C} / \mathrm{min}$ and the data was collected from $0{ }^{\circ} \mathrm{C}$ to $150{ }^{\circ} \mathrm{C}$. The samples dimensions were $35.0(\mathrm{~L}) \times 12.6(\mathrm{~W}) \times 3.2(\mathrm{~T})$ $\mathrm{mm}^{3}$ and three specimens were tested for each composition.

Flexural Testing: Flexural tests were performed according to ASTM D790-10, three point bending configuration, using an Instron machine, model 5569 and load cell of $50 \mathrm{kN}$. At least 5 samples were tested for each composition.

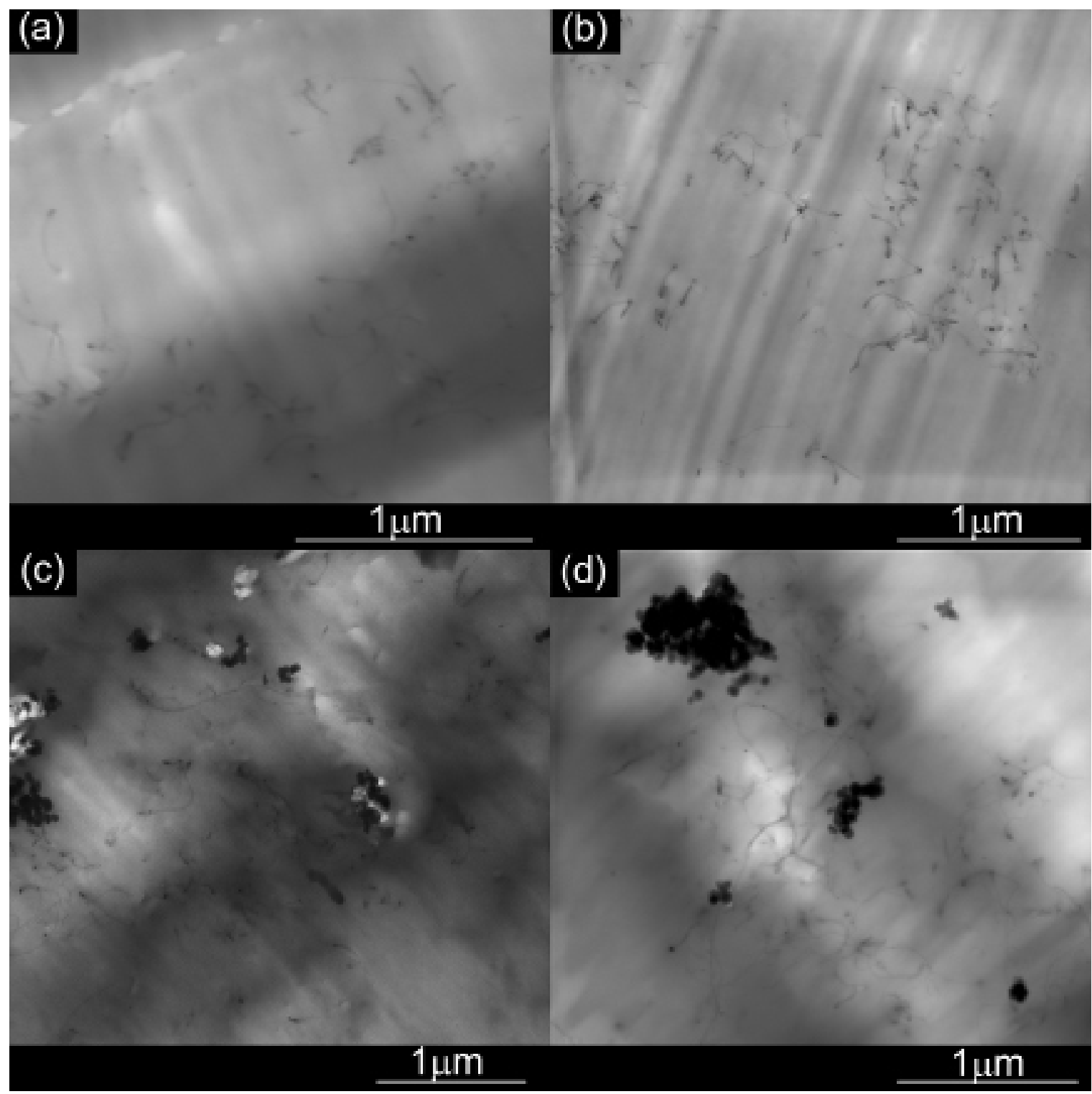

Figure 1. TEM micrographs C1 and C2: (a) C1 130.000x, (b) C2 100.000x, (c) C1C 80.500x, (d) C2C 100.000x. 


\section{Results and Discussion}

The main goal of this work was to investigate the influence of the addition of calcium carbonate in electrical, mechanical, thermal and thermomechanical properties of epoxy/CNT nanocomposites.

\subsection{Morphology Analysis}

Figure $1 \mathrm{a}$ and $1 \mathrm{~b}$ show the micrographs of nanocomposites $\mathrm{C} 1$ and $\mathrm{C} 2$ respectively. In both micrographs, it is possible to verify good dispersion (absence of CNT bundles) of CNT in epoxy matrix. However, a qualitative analysis of the carbon nanotubes dispersion showed that these CNT presented a reduction in the overall length, compared to the information provided by the supplier. This reduction in the size of the CNT was already expected, once ultrasonication generates high shear stress leading to reduce the length of the $\mathrm{CNT}^{7,26,27}$.

Figure 1c and 1d show the micrographs of $\mathrm{C} 1 \mathrm{C}$ and $\mathrm{C} 2 \mathrm{C}$, respectively. It is possible to notice a good dispersion of CNT and only few calcium carbonate agglomerates in epoxy matrix. Figure 1c shows regions that only contain CNT and others regions only with calcium carbonate. These micrographs obtained are in agreement with the mechanism proposed by Bao et al., where the calcium carbonate reduces the volume available for CNT to form conductive pathways and also there are regions with only carbon nanotubes that are formed around the epoxy/calcium carbonate regions ${ }^{24}$.

Figures 1d presents micrographs of $\mathrm{C} 2 \mathrm{C}$ composition. The micrographs present a similar microstructure to $\mathrm{C} 1 \mathrm{C}$ composition, however due to the higher content of CNT in this nanocomposite, the CNT present moderate level of agglomeration compared to $\mathrm{C} 1 \mathrm{C}$ composition. Nonetheless, this behavior was already expected because calcium carbonate act restricting the free volume that CNT can occupy and, as the content of CNT increase, greater the tendency of bundles formation.

\subsection{Electrical Properties}

Figure 2 shows the electrical conductivity of epoxy and epoxy/CNT nanocomposites at $1 \mathrm{~Hz}$ for different contents of CNT. It can be noted that neat epoxy presents very small electrical conductivity at $1 \mathrm{~Hz}$, whereas in nanocomposites with low contents of CNT, e.g. C1 which has $0.05 \mathrm{wt} \%$, the increase in electrical conductivity is almost 2 decades when compared to neat epoxy. As further CNT are added in epoxy/ CNT nanocomposites, the content of CNT overcome the electrical percolation threshold and the number of conductive pathways increases. As more conductive pathways are formed, higher is the current transported through the material ${ }^{28}$.

Using the Equation 1 in the collected data, $\theta_{c}$ and $t$ for epoxy/CNT nanocomposites values were determined. The values calculated for $\theta_{\mathrm{c}}$ and $t$ are $\theta_{\mathrm{c}}=1.83 \times 10^{-2} \mathrm{v} / \mathrm{v}$ and $\mathrm{t} \sim$ 2 . The value of $\theta_{c}$ is in good agreement with recent studies, and it is almost the correspondent weight percent of $0.05 \mathrm{wt}$

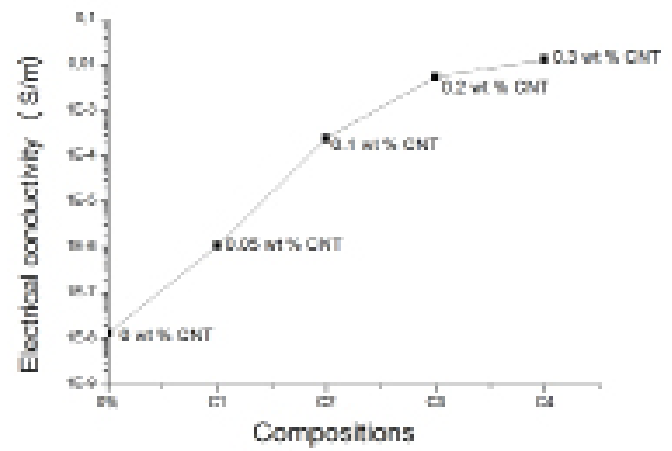

Figure 2. Electrical conductivity of epoxy and epoxy/CNT nanocomposites at $1 \mathrm{~Hz}$.

$\% \%^{2,18,29}$. The value obtained for critical exponent is related to a three dimensional dispersion ${ }^{19}$.

Figure 3 presents electrical conductivity of the epoxy and epoxy/CNT nanocomposites as a function of frequency. Epoxy matrix presents a quasi linear behavior for electrical conductivity against frequency that is typical for polymers which exhibits dipolar relaxation ${ }^{30,31}$. Nanocomposite $\mathrm{C} 1$ shows a 2-decade increase in the electrical conductivity compared to neat epoxy and the electrical conductivity remains constant from $1 \mathrm{~Hz}$ to $100 \mathrm{~Hz}$. It seems that the CNT reduce the mobility of epoxy dipoles at low frequencies and only after $100 \mathrm{~Hz}$ the dipolar relaxation mechanism are significant and affect electrical conductivity. Electrical properties are in good agreement with morphological results, once the good dispersion of CNT in epoxy matrix resulted in an improvement in electrical properties even for low CNT contents.

The nanocomposite $\mathrm{C} 2$ presented a behavior similar to $\mathrm{C} 1$, but due the higher CNT concentration, the electrical conductivity increase by 4 decades compared to neat epoxy and the CNT reduced further the epoxy's dipolar mobility, once the electrical conductivity remained constant up to $30 \mathrm{kHz}$.

Nanocomposites C3 and C4 presented further increase in electrical conductivity and it became almost linear against

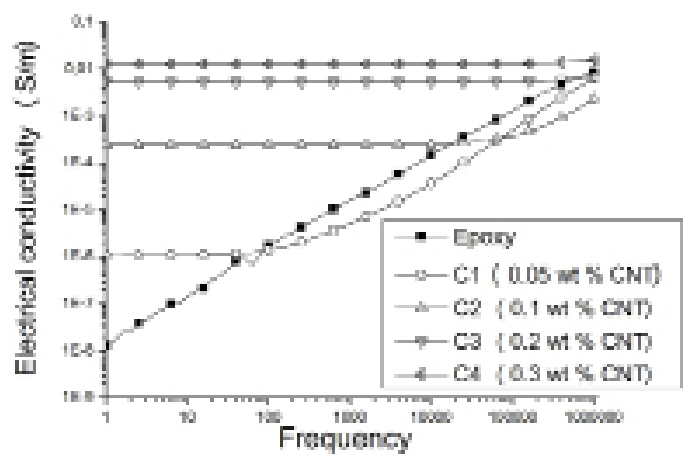

Figure 3. Electrical conductivity as function of frequency for neat epoxy and epoxy/CNT nanocomposites. 
frequency, exemplifying a huge number of conductive pathways formed by CNT.

Figure 4 presents electrical conductivity of the epoxy/ $\mathrm{CNT} /$ calcium carbonate nanocomposites as a function of the frequency. $\mathrm{C} 1 \mathrm{C}$ and $\mathrm{C} 2 \mathrm{C}$ nanocomposites showed improvements in electrical conductivity caused by calcium carbonate addition. The $\mathrm{C} 1 \mathrm{C}$ electrical conductivity at $1 \mathrm{~Hz}$ was $2.82 \times 10^{-6} \mathrm{~S} / \mathrm{m}$, almost three times higher than $\mathrm{C} 1$ electrical conductivity and 2 decades higher than neat epoxy. This electrical behavior is a function of microstructure obtained in $\mathrm{C} 1 \mathrm{C}$, in which the calcium carbonate particles are well dispersed and act restricting the free volume that CNT can occupy. Therefore, CNT conductive pathways are formed only in areas without calcium carbonate.

Analyzing $\mathrm{C} 2 \mathrm{C}$ electrical properties, there is nearly any distinction between $\mathrm{C} 2 \mathrm{C}$ and $\mathrm{C} 2$ electrical conductivity, once $\mathrm{C} 2 \mathrm{C}$ and $\mathrm{C} 2$ nanocomposites have $\mathrm{CNT}$ contents higher than the percolation threshold, the effect of volume exclusion originated by calcium carbonate addition is less effective. $\mathrm{C} 2 \mathrm{C}$ micrograph (Figure 2b) also shows that the higher concentration of $\mathrm{CNT}$ in the nanocomposite and the presence of calcium carbonate promotes more agglomeration of CNT.

\subsection{Thermal Analysis}

Figure 5 shows the DSC curves for neat epoxy, epoxy/CNT nanocomposites with 0.05 and $0.1 \mathrm{wt} \%$ of CNT and epoxy/ $\mathrm{CNT} /$ calcium carbonate with 0.05 and $0.1 \mathrm{wt} \%$ of CNT. The addition of CNT and calcium carbonate in epoxy matrix can play different roles on $\mathrm{T}_{\mathrm{g}}$. According Putz et al. there are two main mechanisms that can displace the $\mathrm{T}_{\mathrm{g}}$ of the nanocomposites ${ }^{32}$. In the first case, there is an increase in $\mathrm{T}_{\mathrm{g}}$ due to the creation of an interphase between CNT and epoxy that restrict polymers mobility. In the second mechanism, the CNT lead to a network disruption, decreasing the cross-link density and reducing $\mathrm{T}_{\mathrm{g}}$.

Table 1 shows the glass transition obtained by DSC measurements. It is noticed that $\mathrm{CNT}$ and calcium carbonate did not lead to huge changes in nanocomposites $\mathrm{T}_{g}$. The nanocomposites $\mathrm{C} 1, \mathrm{C} 1 \mathrm{C}$ and $\mathrm{C} 2$ presented little change

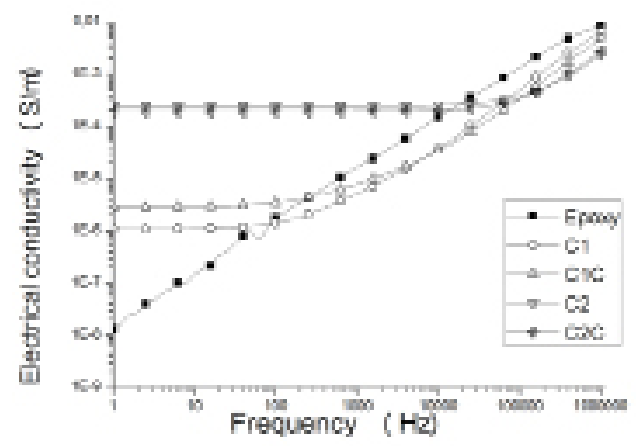

Figure 4. Electrical conductivity as function of frequency for neat epoxy, epoxy/CNT nanocomposites with 0.05 and $0.1 \mathrm{wt} \%$ of CNT and epoxy/CNT/calcium carbonate with 0.05 and $0.1 \mathrm{wt} \%$ of CNT.

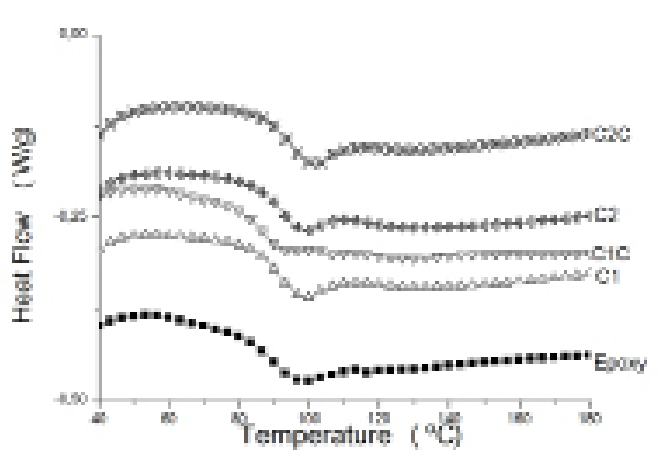

Figure 5. DSC curves for neat epoxy, epoxy/CNT nanocomposites with 0.05 and $0.1 \mathrm{wt} \%$ of CNT and epoxy/CNT/calcium carbonate with 0.05 and $0.1 \mathrm{wt} \%$ of CNT.

Table 1. Glass transitions $\left(\mathrm{T}_{\mathrm{g}}\right)$ for neat epoxy, epoxy/CNT nanocomposites with 0.05 and $0.1 \mathrm{wt} \%$ of CNT and epoxy/CNT/ calcium carbonate with 0.05 and $0.1 \mathrm{wt} \%$ of CNT obtained by DSC.

\begin{tabular}{cc}
\hline Nanocomposites & $\left.\mathrm{T}_{\mathrm{g}}{ }^{\circ} \mathrm{C}\right)$ \\
\hline Epoxy & $89 \pm 1$ \\
C1 & $90 \pm 2$ \\
C1C & $89 \pm 2$ \\
C2 & $92 \pm 2$ \\
C2C & $94 \pm 2$ \\
\hline
\end{tabular}

in the $\mathrm{T}_{\mathrm{g}}$ and only $\mathrm{C} 2 \mathrm{C}$ showed a higher increase in $\mathrm{T}_{\mathrm{g}}$ compared to neat epoxy.

Although, the good dispersion of the CNT and calcium carbonate in epoxy, the nanocomposites have low fillers concentrations, max. $1 \mathrm{wt} \%$ of calcium carbonate and maximum $0.1 \mathrm{wt} \%$ of CNT, and at these levels only nanocomposite $\mathrm{C} 2 \mathrm{C}$ presented synergic effect between $\mathrm{CNT}$ and calcium carbonate leading to an increase in $\mathrm{T}_{\mathrm{g}}$. It is possible that, due to good dispersion of CNT and calcium carbonates, these create more interphase volume between CNT and epoxy.

However, when ANOVA-Test is performed for these compositions, it is observed that despite the improvements observed in $\mathrm{C} 2 \mathrm{C}$, the samples groups are identical once $\mathrm{p}$-value obtained was higher than $0.05(\mathrm{p}=0,08)$. Fidelus et al. studied also epoxy/CNT nanocomposites and no change in $\mathrm{T}_{\mathrm{g}}$ was observed in nanocomposites with $0.5 \mathrm{wt} \% \mathrm{CNT}^{33}$. It is important to notice that the amount of CNT used for Fidelus et al. was 5 times higher than those used in this work. According to Prolongo et al. the reduction in $\mathrm{T}_{\mathrm{g}}$ in their nanocomposites was related to CNT agglomeration, however this behavior was not observed since CNT are well dispersed in epoxy matrix, as observed in micrographs (Fig.1 a-d) ${ }^{34}$.

\subsection{Dynamic Mechanical Analysis (DMA)}

Figure 6a shows storage modulus (E') for neat epoxy, epoxy/CNT nanocomposites with 0.05 and $0.1 \mathrm{wt} \%$ of CNT 

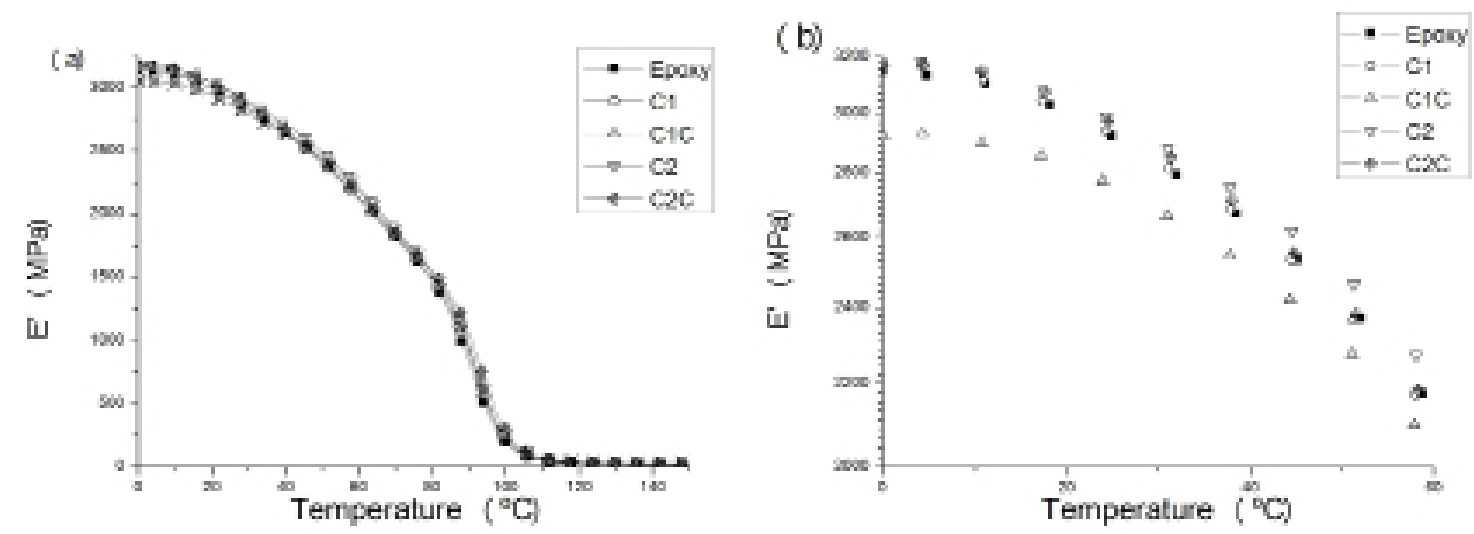

Figure 6. Storage modulus versus temperature for neat epoxy, epoxy/CNT nanocomposites with 0.05 and 0.1 wt \% of CNT and epoxy/ $\mathrm{CNT} /$ calcium carbonate with 0.05 and $0.1 \mathrm{wt} \%$ of CNT. (a) Storage modulus versus temperature from $0{ }^{\circ} \mathrm{C}$ to $150{ }^{\circ} \mathrm{C}$, (b) Storage modulus versus temperature from $0{ }^{\circ} \mathrm{C}$ to $60^{\circ} \mathrm{C}$.

Table 2. Storage modulus determined via DMA for neat epoxy, epoxy/CNT nanocomposites with 0.05 and $0.1 \mathrm{wt} \%$ of CNT and epoxy/CNT/calcium carbonate with 0.05 and $0.1 \mathrm{wt} \%$ of CNT.

\begin{tabular}{cc}
\hline Composition & Storage Modulus@ $23^{\circ} \mathrm{C}(\mathrm{MPa})$ \\
\hline Epoxy & $2800 \pm 204$ \\
C1 & $2831 \pm 261$ \\
C1C & $2768 \pm 119$ \\
C2 & $2977 \pm 34$ \\
C2C & $2824 \pm 127$ \\
\hline
\end{tabular}

Table 3. Flexural properties of neat epoxy, epoxy/CNT nanocomposites with 0.05 and $0.1 \mathrm{wt} \%$ of CNT and epoxy/CNT/calcium carbonate with 0.05 and $0.1 \mathrm{wt} \%$ of CNT.

\begin{tabular}{cccc}
\hline Nanocomposites & $\begin{array}{c}\text { Flexural } \\
\text { Modulus } \\
(\mathrm{GPa})\end{array}$ & $\begin{array}{c}\text { Flexural } \\
\text { strength at } \\
\text { break (MPa) }\end{array}$ & $\begin{array}{c}\text { Elongation } \\
(\%)\end{array}$ \\
\hline Epoxy & $2.71 \pm 0.10$ & $96.6 \pm 3.7$ & $4.9 \pm 0.17$ \\
C1 & $2.89 \pm 0.05$ & $102.8 \pm 1.6$ & $4.7 \pm 0.33$ \\
C1C & $2.89 \pm 0.11$ & $99.1 \pm 7.2$ & $4.6 \pm 0.40$ \\
C2 & $2.97 \pm 0.18$ & $104.0 \pm 1.2$ & $5.00 \pm 0^{\mathrm{a}}$ \\
C2C & $2.93 \pm 0.13$ & $101.2 \pm 6.7$ & $4.69 \pm 0.42$ \\
\hline
\end{tabular}

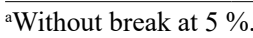

and epoxy/CNT/calcium carbonate with 0.05 and $0.1 \mathrm{wt}$ $\%$ of CNT. All the nanocomposites present similar trends, e.g., reduction of the storage modulus as the temperature increases. Neat epoxy presented storage modulus of 2.8 $\mathrm{MPa}$ at $23^{\circ} \mathrm{C}$ and it almost the same as the flexural modulus obtained by Sene et al. ${ }^{29}$.

The addiction of CNT and calcium carbonate in epoxy matrix did not seems to influence the storage modulus and based on this Chen et al. proposed some correlations between electrical properties (electrical percolation threshold) and mechanical properties (stiffness threshold) versus CNT networks morphology that helps to understand this behavior $^{35}$. According Chen et al. there are 4 different kind of morphologies that CNT can assume. First, for very low CNT contents, there are just a few contacts between CNT and the CNT are not enough to form conductive pathways neither carry load ${ }^{35}$. However when CNT content is near the percolation threshold, there is an increase in electrical conductivity but the nanocomposite is still not able to carry load and the increases in mechanical properties are minimal. Higher contents of CNT in nanocomposites provide a denser CNT network with more connections between CNT, higher electrical conductivity and an increase in the stiffness of the nanocomposite. Once the electrical percolation threshold was determined to be around $0.05 \mathrm{wt} \%$ of CNT, nanocomposites $\mathrm{C} 1$ and $\mathrm{C} 1 \mathrm{C}$ have low potential for increasing mechanical properties (below stiffness threshold), despite this, they presented remarkable increase in electrical conductivity. C2 and $\mathrm{C} 2 \mathrm{C}$ possess higher $\mathrm{CNT}$ contents than the percolation threshold, but both didn't seem to reach the stiffness threshold and, because of that, the mechanical properties remain unchanged.

Table 2 summarizes DMA results for the materials analyzed. The ANOVA-Test was performed for the samples and $p$-value obtained was $p=0.4$, exemplifying that there are no significant different between the samples. This behavior is probably due the low content of CNT that are not able to impart to the composite stiffness beyond the threshold and generate significant changes in mechanical behavior.

\subsection{Flexural Properties}

Table 3 presents flexural properties for neat epoxy, epoxy/ CNT nanocomposites with 0.05 and $0.1 \mathrm{wt} \%$ of CNT and epoxy/CNT/calcium carbonate with 0.05 and $0.1 \mathrm{wt} \%$ of CNT. Neat epoxy presented flexural modulus of $2.71 \mathrm{GPa}$ and this value is almost the same of the epoxy storage modulus at $23^{\circ} \mathrm{C}$. For $\mathrm{C} 1$ and $\mathrm{C} 1 \mathrm{C}$ nanocomposites, an increase of $6 \%$ flexural modulus is noticed, flexural strength and at break remain unchanged. $\mathrm{C} 2$ nanocomposite presented increase 
of $8 \%$ in flexural modulus when compared to $\mathrm{C} 1, \mathrm{C} 1 \mathrm{C}$ and $10 \%$ when compared to neat epoxy. In this nanocomposite, the CNT seem to toughen the nanocomposite, once any sample broke at $5 \%$ elongation. For the other samples, the elongation remain unchanged. The significance of the flexural modulus results was confirmed by ANOVA-Test and $p$-value of 0,012 was obtained, confirming the difference between the groups analyzed.

A small tendency increasing flexural strength at break for all nanocomposites was observed, however ANOVA-test present $p$-value of 0,16 indicating that no significant changes in this property is observed. Flexural strength at break stood between $99.1 \mathrm{MPa}$ and 102.8 $\mathrm{MPa}$.

\section{Conclusions}

Epoxy/CNT nanocomposites with low electrical percolation threshold were produced via in situ polymerization and it was noticed that the addition of calcium carbonate in these nanocomposites led to a new microstructure, in which the calcium carbonate particles reduced the volume that CNT can occupy in epoxy matrix. Significant improvement in electrical properties were observed by adding calcium carbonate in epoxy/CNT nanocomposites, e.g., C1C presented electrical conductivity at $1 \mathrm{~Hz}$ three times higher than $\mathrm{C} 1$ and 2 decades higher than neat epoxy. Regarding thermal properties, an increase in $\mathrm{T}_{\mathrm{g}}$ for $\mathrm{C} 2 \mathrm{C}$ was observed, however the ANOVAtest showed no significant changes between groups. The same behavior was observed for storage modulus, due to low content of CNT that are no able to impart to the composite stiffness beyond the threshold. Regarding flexural modulus $\mathrm{C} 2$ and $\mathrm{C} 2 \mathrm{C}$ presented improvements from almost $10 \%$ when compared to neat epoxy and it is due the creation of epoxy/ calcium carbonate interphase that restrict polymers mobility.

\section{Acknowledgements}

The authors would like to thank the São Paulo Research Foundation (FAPESP) for financially supporting this research under process number 2014/16299-8.

The authors would like to thank the National Council for Scientific and Technological Development (CNPq) for financially supporting this research under process number 1309 978/2014-0.

\section{References}

1. Ma PC, Siddiqui NA, Marom G, Kim JK. Dispersion and functionalization of carbon nanotubes for polymer-based nanocomposites: A review. Composites Part A: Applied Science and Manufacturing. 2010;41(10):1345-1367.

2. Mittal G, Dhand V, Rhee KY, Park SJ, Lee WR. A review on carbon nanotubes and graphene as fillers in reinforced polymer nanocomposites. Journal of Industrial and Engineering Chemistry. 2015;21:11-25.
3. Iijima S. Helical microtubules of graphitic carbon. Nature. 1991;354(6348):56-58.

4. Hosur M, Barua R, Zainuddin S, Kumar A, Trovillion J, Jeelani $\mathrm{S}$. Effect of processing techniques on the performance of Epoxy/ MWCNT nanocomposites. Journal of Applied Polymer Science. 2013;127(6):4211-4224.

5. Huang YY, Terentjev EM. Dispersion of Carbon Nanotubes: Mixing, Sonication, Stabilization, and Composite Properties. Polymers (Basel). 2012;4(1):275-295.

6. Pal G, Kumar S. Modeling of carbon nanotubes and carbon nanotube-polymer composites. Progress in Aerospace Sciences. 2015;80:33-58

7. Korayem AH, Barati MR, Chen SJ, Simon GP, Zhao XL, Duan WH. Optimizing the degree of carbon nanotube dispersion in a solvent for producing reinforced epoxy matrices. Powder Technology. 2015;284:541-550.

8. Guadagno L, Vietri U, Raimondo M, Vertuccio L, Barra G, De Vivo B, et al. Correlation between electrical conductivity and manufacturing processes of nanofilled carbon fiber reinforced composites. Composites Part B: Engineering. 2015;80:7-14.

9. Jin FL, Park SJ. Recent Advances in Carbon-Nanotube-Based Epoxy Composites. Carbon Letters. 2013;14(1):1-13.

10. Sabet SM, Mahfuz H, Hashemi J, Nezakat M, Szpunar JA. Effects of sonication energy on the dispersion of carbon nanotubes in a vinyl ester matrix and associated thermo-mechanical properties. Journal of Materials Science. 2015;50(13):4729-4740.

11. Nadler M, Werner J, Mahrholz T, Riedel U, Hufenbach W. Effect of CNT surface functionalisation on the mechanical properties of multi-walled carbon nanotube/epoxy-composites. Composites Part A: Applied Science and Manufacturing. 2009;40(6-7):932-937.

12. Zakaria MR, Akil HM, Abdul Kudus MH, Kadarman AH. Improving flexural and dielectric properties of MWCNT/epoxy nanocomposites by introducing advanced hybrid filler system. Composite Structures. 2015;132:50-64.

13. Yoonessi M, Lebrón-Colón M, Scheiman D, Meador MA. Carbon Nanotube Epoxy Nanocomposites: The Effects of Interfacial Modifications on the Dynamic Mechanical Properties of the Nanocomposites. ACS Applied Materials \& Interfaces. 2014;6(19):16621-16630.

14. Azeez AA, Rhee KY, Park SJ, Hui D. Epoxy clay nanocomposites - processing, properties and applications: A review. Composites Part B: Engineering. 2013;45(1):308-320.

15. Huang YY, Terentjev EM, Huang BYY. Tailoring the Electrical Properties of Carbon Nanotube-Polymer Composites. Advanced Functional Materials. 2010;20(23):4062-4068.

16. Ivanov E, Kotsilkova R, Krusteva E, Logakis E, Kyritsis A, Pissis P, et al. Effects of processing conditions on rheological, thermal, and electrical properties of multiwall carbon nanotube/ epoxy resin composites. Journal of Polymer Science Part B Polymer Physics. 2011;49(6):431-442.

17. Hennrich F, Krupke R, Arnold K, Rojas Stütz JA, Lebedkin S, Koch T, et al. The Mechanism of Cavitation-Induced Scission of Single-Walled Carbon Nanotubes. The Journal of Physical Chemistry B. 2007;111(8):1932-1937. 
18. Sandler JKW, Kirk JE, Kinloch IA, Shaffer MSP, Windle AH. Ultra-low electrical percolation threshold in carbon-nanotubeepoxy composites. Polymer. 2003;44(19):5893-5899.

19. Russ M, Rahatekar SS, Koziol K, Farmer B, Peng HX. Length-dependent electrical and thermal properties of carbon nanotube-loaded epoxy nanocomposites. Composites Science and Technology. 2013;81:42-47.

20. Castellino M, Chiolerio A, Shahzad MI, Jagdale PV, Tagliaferro A. Electrical conductivity phenomena in an epoxy resin-carbonbased materials composite. Composites Part A: Applied Science and Manufacturing. 2014;61:108-114.

21. Guadagno L, Naddeo C, Vittoria V, Sorrentino A, Vertuccio L, Raimondo M, et al. Cure behavior and physical properties of epoxy resin-filled with multiwalled carbon nanotubes. Journal of Nanoscience and Nanotechnology. 2010;10(4):2686-2893.

22. Ayatollahi MR, Shadlou S, Shokrieh MM, Chitsazzadeh M. Effect of multi-walled carbon nanotube aspect ratio on mechanical and electrical properties of epoxy-based nanocomposites. Polymer Testing. 2011;30(5):548-556.

23. Liu L, Grunlan JC. Clay Assisted Dispersion of Carbon Nanotubes in Conductive Epoxy Nanocomposites. Advanced Functional Materials. 2007;17(14):2343-2348.

24. Bao HD, Guo ZX, Yu J. Effect of electrically inert particulate filler on electrical resistivity of polymer/multi-walled carbon nanotube composites. Polymer. 2008;49(17):3826-3831.

25. Montazeri A, Chitsazzadeh M. Effect of sonication parameters on the mechanical properties of multi-walled carbon nanotube/ epoxy composites. Materials \& Design (1980-2015). 2014;56:500508.

26. Vahedi F, Shahverdi HR, Shokrieh MM, Esmkhani M. Effects of carbon nanotube content on the mechanical and electrical properties of epoxy-based composites. New Carbon Materials. 2014;29(6):419-425.
27. Yang RB, Kuo WS, Lai HC. Effect of carbon nanotube dispersion on the complex permittivity and absorption of nanocomposites in 2-18 GHz ranges. Journal of Applied Polymer Science. 2014;131(21):40963.

28. Balakrishnan A, Saha MC. Tensile fracture and thermal conductivity characterization of toughened epoxy/CNT nanocomposites. Materials Science and Engineering: A. 2011;528(3):906-913.

29. Martin CA, Sandler JKW, Windle AH, Schwarz MK, Bauhofer $\mathrm{W}$, Schulte K, et al. Electric field-induced aligned multi-wall carbon nanotube networks in epoxy composites. Polymer. 2005;46(3):877-886.

30. Sene TS, Ramos A, Becker D, Coelho LAF. Electrical conductivity behavior of epoxy matrix nanocomposites with simultaneous dispersion of carbon nanotubes and clays. Polymer Composites. 2016;37(5):1603-1611.

31. Singha S, Thomas MJ. Dielectric properties of epoxy nanocomposites. IEEE Transactions on Dielectrics and Electrical Insulation. 2008;15(1):12-23.

32. Arjmand M, Apperley T, Okoniewski M, Sundararaj U. Comparative study of electromagnetic interference shielding properties of injection molded versus compression molded multi-walled carbon nanotube/polystyrene composites. Carbon. 2012;50(14):5126-5134.

33. Fidelus JD, Wiesel E, Gojny FH, Schulte K, Wagner HD. Thermo-mechanical properties of randomly oriented carbon/ epoxy nanocomposites. Composites Part A: Applied Science and Manufacturing. 2005;36(11):1555-1561.

34. Prolongo SG, Melitón BG, Jiménez-Suárez A, Ureña A. Study of efficiency of different commercial carbon nanotubes on manufacturing of epoxy matrix composites. Journal of Composite Materials. 2013;48(25):3169-3177.

35. Chen Y, Pan F, Guo Z, Liu B, Zhang J. Stiffness threshold of randomly distributed carbon nanotube networks. Journal of the Mechanics and Physics of Solids. 2015;84:395-423. 